\title{
A METHOD FOR THE EXAMINATION OF WATER BIOLOGICALLY.
}

H. S. Carpenter, F.I.C., F.C.S., and W. O. Nicholson, F.C.S.

Read before the Society of Public Analysts, on April 16th, 1884.

THE germ theory of disease, though essentially of modern growth, is yet not by any means new. And although held with unfaltering faith by a large proportion of the most eminent scientific men of the day, it has certainly not met with such general acceptance from those to whom it would appear to be of the first importance-the medical profession.

It is perhaps scarcely within our province to enter here into a controversy in favour of this theory ; the brilliant researches of Pasteur, Koch and others, must be too well known to members of this Society to make reference to them necessary. Neither is it desirable that we should endeavour to sum up the arguments of those who do not accept it. But we feel bound to add that the very large and constantly accumulating amount of corroborative evidence that it has received of late years would seem to lead irresistibly to the conclusion that the day eannot be far off when it will be accepted as a scientific fact.

Those who, with us, hold this view, will at once admit the importance of the subject; which, indeed, it is almost impossible to over-estimate. To those, on the other hand, who hold the contrary opinion, this paper will be of little interest from a hygienic point, though possibly it may be of some biologically.

No doubt all amongst us will remember Dr. Frankland's reference to an outbreak of typhoid fever at Lausen, in Switzerland, in a paper read before the Chemical Society in November, 1876, the evidence being indisputable that the disease was conveyed by the water supply, and, in fact, we are constantly being reminded of the part which water plays in the propagation of certain diseases, either directly, or perhaps, through the agency of the milk-can.

It therefore appears to be of the greatest value that some method should be devised for detecting the presence or absence of bacterial organisms in water. Such a method we are about to lay before you to-night.

It is, no doubt, a fact that, under certain conditions, these bacterial organisms may be taken in countless myriads, without any bad results arising. Therefore not until it is possible to distinguish between the injurious and non-injurious ones shall we be able to say with certainty as to whether a water will cause disease or not. In the present state of our knowledge we ourselves should be inclined to hold that ouly a water perfertly free from these organisms is entirely safe. 
However, we do claim that we have made a distinct advance, and an advance in a direction which, without, we hope, undue confidence, may be reasonably anticipated to lead to more valuable results than can be obtained from a purely chemical examination.

It is quite conceivable that a sample of water may contain so small a number of organisms or their germs, that very possibly none of them may be brought within the limited field of the droplet under the microscope.

The method we are about to lay before you has been devised for the purpose of fostering the growth and reproduction of any organisms (vegetable) present in the water, so that, by reason of their increased number, they may readily be detected.

The principal difficulty that confronted us was the prevention of the access of any adventitious germs present in the atmosphere. This we hope to have satisfactorily overcome.

The apparatus employed by us consists (i) of a propagating vessel. For this we use a short-necked four-ounce flask which is fitted with a caoutchouc stopper, through which pass two tubes, bent at right angles, slightly drawn out, so as to admit of their being readily fused up.

(ii). A transferring vessel. This is a tube having a bulb capable of containing about 25 c.c. blown upon the side.

(iii). A tube for sterilising the air necessary to be supplied. This is simply a piece of combustion tubing about 18 inches long, 9 or 10 inches of it being loosely packed with asbestos and which can be connected with a refrigerator.

We then proceed as follows:- Into the propagating flask 50 c.c. or thereabouts of Pasteur's solution, previously filtered and recently boiled, are introduced. This is then boiled for some time and whilst steam is still issuing the tubes are plugged with cotton wool (sterilised).

The sterilising tube is then attached and kept at a red heat and the flask is again boiled, whilst a current of sterilised air slowly passes. After a short time the tubes are sealed up hot.

We thus have a flask containing a fluid, devoid of life, but admirably adapted for supporting lower organisms.

Now for the sample. The two ends of the triansferring bulb are drawn out to fine points, and one is sealed up. A little distilled water is then introduced and the bulb heated in a calcium chloride bath till the water is dissipated, after which the point is sealed. The bulb thus contains practically nothing but aqueous vapour. One end is now broken off 3 or 4 inches under the surface of the sample water, to be examined; the water rushes up and nearly fills the bulb; the point is then immediately sealed. The next step is to introduce the sample of water in the bulb into the propagating flask.

Having heated the sterilising tube, and attached the refrigerator, a rapid current of air is par sed for some time in order to clear the apparatus. One of the points of the transferring bulb is then passed through a flame in order to destroy possibly adherent germs and connected with the refrigerator; the other point of the bulb tube, and 
the point of the propagating flask, are heated in a similar manner, and connected by a piece of india-rubber tubing, which has just been taken out of boiling distilled water.

The refrigerator is now surrounded with cold water and the several points are broken off by pressure on the rubber connections.

Owing to the lesser pressure (partial vacuum) in the flask, the water speedily passes over, followed by sterilised air, after which all that has to be done is to seal up and disconnect.

The propagating flask is afterwards removed to any convenient place where it is exposed to the light and can be kept at a suitable temperature and is examined daily, so that the first appearance of any turbidity may be observed.

In the case of waters contaminated with sewage we find this usually occurs in 2 to 4 days, whilst with waters that are tolerably pure 7 to 10 days are required.

The extent and general appearance of the cloudiness enables us to form some opinion as to the desirability of the sample; and a careful microscopical examination with high powers, made immediately after the opening of the flask, reveals the nature of the organisms. We use a $\frac{1}{4}, \frac{1}{8}, \frac{1}{16}$, and $\frac{1}{2} 5$, in succession and have found that whilst some waters contain various kinds of bacteria, yeast, and other organisms, in others only an unicellular fungus or confervoid growth can be distinguished.

We may add that the Thames water supplied by some of the London companies provides a fine variety of organisms.

It is our intention to examine a much larger number of waters, from all parts of the kingdom, in this manner, and shall be very much obliged if at any time any member of this Society can favour us either with a pure sample of water or of one which may reasonably be suspected of propagating diseases. 